\title{
Investigation of Water Distribution Characteristics for Large Cannon Irrigation Sprinkler under different Spacing and Layouts
}

\section{ISSAKA Zakaria1', ISSAH Mohammed Hardi', YAMBA Phillip²}

${ }^{1}$ Department of Agricultural Engineering, Tamale Technical University, Tamale, Northern Region, Ghana.

${ }^{2}$ Department of Mechanical Engineering, Tamale Technical University, Tamale, Northern Region, Ghana.

Article No.: 040618056

Type: Research

DOI: 10.15580/GJSETR.2018.1.040618056

Submitted: 06/04/2018

Accepted: 18/04/2018

Published: $25 / 05 / 2018$

${ }^{*}$ Corresponding Author

Zakaria ISSAKA

E-mail: issakazak@gmail.com

Phone: +233206323080

Keywords: large cannon sprinkler; water distribution; uniformity; spacing \& layouts
Relevant factors affecting the irrigation performance of large cannon sprinkler include the nozzle diameter, operating pressure, layout form, and overlapping distance, which were studied under no wind conditions. The discharge coefficient ranged from 0.96 to 0.99 . A mathematical model of radius of throw was regressed and the coefficient of determination was $\mathbf{0 . 9 7 6 5}$. The application rate was lower near the sprinkler, and the highest value occurred under the radius of throw from 4 to $6 \mathrm{~m}$ for each water distribution pattern. The average application rate decreased with increase in operating pressure. The average application rate increased with the increase in nozzle diameter. The increased or decreased in magnitude of average application rate under small nozzle diameter was larger than the large nozzle diameter for the same range pressure variations. The maximum $\mathrm{CU}$ values increased with increase in pressure under different nozzle diameter or different layouts. Triangular layout gave higher uniformities compared with square layout. The optimal $\mathrm{CU}$ values and spacing coefficients of large cannon sprinkler with different layouts, pressure and nozzle diameter were proposed. 


\section{INTRODUCTION}

Sprinkler irrigation is being widely used due to the operational simplicity that it offers. Furthermore, this method of irrigation provides a good water distribution uniformity, precise control of the depth of application, high water application, efficiency and potential use in different types of soil and topography conditions (Bernardo et al., 2006; Frizzone et al., 2011).

Sprinkler equipment is the main component of a sprinkler irrigation system, which serve the purpose to distribute water over an area so that the appropriate amount of water is applied in all area. In order to understand what to expect from any sprinkler that designer plan to use, some general characteristics need to be understood. These include sprinkler discharge, radius of throw, water distribution pattern and precipitation rate. For combination application, sprinkler layout is one of the important decisions to design an irrigation system. A poor design will likely result in uneven water distribution with more water in some areas than others. There are three basic choices in sprinkler layout; triangular, rectangular and square layouts.

Water application uniformity is influenced by many factors, controlled or not by the operator. Among the factors that can be controlled by the operator are: i) geometric shape of the radial leg, which depends on the kind of sprinkler, nozzle diameter, operating pressure and trajectory angle; ii) sprinkler layout forms (rectangular and triangular); and iii) overlapping distance) (Bernardo et al., 2006; Keller \& Bliesner, 1990). However, wind (speed and direction) cannot be controlled by the operator (Seginer et al., 1992; Carrión et al., 2001; Faria et al., 2009; Beskow et al., 2011; Faria et al., 2012).

Uniformity of water distribution is an important hydraulic performance characteristic and the most relevant parameter in sprinkler irrigation system. Indeed, this design factor has great influence on important aspects such as water use efficiency, leaching of fertilizers and crop yield (Seginer et al., 1991b; Branscheid \& Hart, 1986.). A non-uniform water distribution not only could leave some parts of the crop on a deficiency in water, but also excessive irrigation, resulting in ponding water, crop damage, soil salinization, and leaching of chemical substances beyond the rootzone (Solomon, 1983). Non-uniform irrigation waste energy and chemicals. Increasing water application uniformity can improve irrigation efficiency by preventing deep percolation and surface runoff caused by over irrigation (James \& Blair 1984).

A great deal of research has already been conducted on the effects of operating pressure, nozzle diameter and layout form on hydraulic performance and water uniformity for small or medium size sprinklers (Culver and Sinker 1966; Chen and Wallender 1985; Edling 1985; Fischer and Wallender 1988; Louie and Selker 2000; Faci et al. 2001; Mateos 2006; Zhu et al. 2012; Liu et al. 2013a; Burillo et al. 2013; Fukui et al.1980; Playán et al. 2006; Zhang et al. 2013). Canessa and Hermanson (1994) indicated that a correct overlap is the result of a correct combination of sprinkler spacing, pressure and nozzle diameter. Burt et al. (1997) indicated that the most influential factors of variations in water distribution are operating pressure variation, sprinkler design, sprinkler layout. Keller and Bliesner (1990) identified that sprinkler irrigation system require a minimum value of water distribution uniformity such as Christiansen's coefficient of uniformity $(\mathrm{CU}) \geq 80 \%$. Low values of $\mathrm{CU}$ are usually indicators of a faulty combination of nozzle diameter, operating pressure and sprinkler spacing (Tarjuelo et al., 1999a). Low values of $\mathrm{CU}$ indicate incorrect combination of nozzle size, operating pressure, and other design factors (Salmerón et al., 2012; Siosemarde et al., 2012; Osman et al., 2014).

Sprinkler irrigation with the large cannon sprinkler is widely used in the world as it allows for the efficient watering of middle-scale fields at relatively low cost (Pascal et al., 2006; Silva, 2006). But, few researches have been conducted on the hydraulic performance and optimal layout of the large cannon sprinkler. Hence, based on the previous studies, the objectives of this paper are: (1) to characterize flow rate and radius of throw on different operating pressures and nozzle diameters on large cannon sprinkler and to propose predictive equations to estimate flow rate and radius of throw using multiple regression; (2) to analyze the water distribution pattern and average application rate; (3) to analyze 
the effect of operating pressure, nozzle diameter, layout form and overlapping distance on water uniformity; (4) to provide optimal values for sprinkler layout to help on design and manage in sprinkle irrigation system with large cannon sprinkler.

\section{MATERIALS AND METHODS}

\section{Sprinkler}

The large cannon sprinkler was selected for this study and it was from the Nelson Irrigation Co., Walla Walla, Washington, USA. Figure 1 presents the photograph of the large cannon sprinkler. The inlet diameter of sprinkler was $38 \mathrm{~mm}$, and the sprinkler jet forms a $24^{\circ}$ angle with respect to the horizontal. Circular nozzle with four different nozzle diameters $(12.5,15.1,19$ and $22.5 \mathrm{~mm}$ ) was selected in this study.

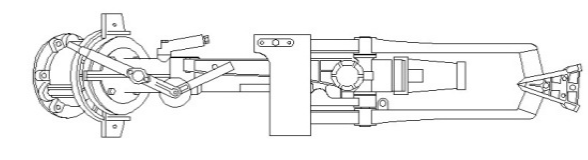

(a)

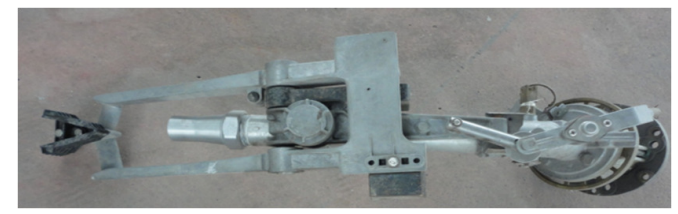

(b)

Figure 1: Photographs of large cannon sprinkler. (a) Schematic diagram of large cannon sprinkler, (b) Picture of real product

\section{Experiment set-up}

Performing experiments in an indoor facility ensures water distribution and avoids water drift and loss
(Sourell et al., 2003; Dukes, 2006; Liu et al, 2013(a)). A schematic of the sprinkler set-up is shown in Figure 2. A centrifugal pump supplied water to the irrigation system from a constant level reservoir. The discharge was measured by an electromagnetic flow meter with an accuracy tolerance of $0.5 \%$. Pressure was measured at the base of the sprinkler head using a pressure gauge with an accuracy tolerance of $0.4 \%$. The catch cans used in the study for testing radial water application were cylindrical in shape with a height of $0.6 \mathrm{~m}$ and an inside diameter of $0.2 \mathrm{~m}$. Catch cans, which were used to collect water, were spaced at $1 \mathrm{~m}$ intervals from the sprinkler in two single collector lines in opposite directions. The water collected in each can was measured using a graduated cylinder. The application rate was calculated based on the diameter of the catch cans and the duration of each test. The radial application rate distributions for the sprinklers were then determined in the laboratory.

The sprinkler heads were installed on a $1.5 \mathrm{~m}$ riser at a $90^{\circ}$ angle to the horizontal and were placed approximately $0.9 \mathrm{~m}$ above the top of the catch cans. The following six operating pressures were tested for the large cannon sprinkler: $300,400,500,600,700$ and $800 \mathrm{kPa}$, respectively. The sprinkler was run for a few minutes before performing the experiments in order to standardize environmental conditions. The following standards were adopted in the design of the experimental set-up and in the experiment itself: ASAE S.330.1 (1985a), ASAE S.398.1 (1985b), and ISO 7749-2 (1990), MOD GB/T 19795.2 (2005). Three repetitions were made for every operating pressure. The volume of water in each catch can was determined as the average of catch cans and for three repetitions.

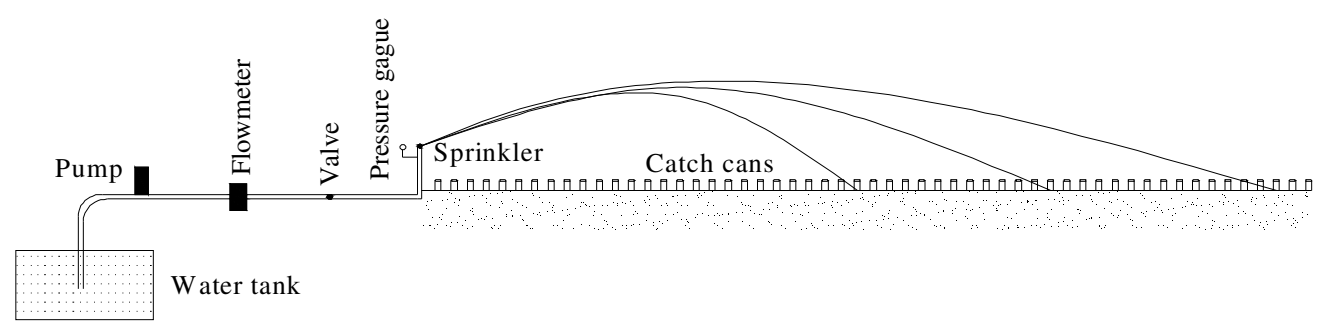

Figure 2: Schematic diagram of the experimental conditions in the laboratory 


\section{Sprinkler water distribution pattern}

Water distribution pattern is useful for designers when choosing the nozzle diameter, operating pressure, layout form and overlapping distance in order to achieve high water distribution uniformity (Tarjuelo et al., 1999c; Carrion et al., 2001).

\section{Sprinkler flow rate}

A relationship which is necessary for designing sprinkler irrigation system have been described between discharge and pressure for an orifice nozzle by Li and Kawano(1998) as follows:

$$
Q=c \cdot A(2 g \cdot H)^{x}
$$

Where: $Q$ is nozzle discharge rate in $\mathrm{m}^{3} \cdot \mathrm{s}^{-1} ; A$ is orifice cross-sectional area in $\mathrm{m}^{2} ; g$ is gravitational acceleration in $\mathrm{m} \cdot \mathrm{s}^{-2}\left(9.8 \mathrm{~m} \cdot \mathrm{s}^{-2}\right) ; H$ is sprinkler pressure head in $\mathrm{m} ; c$ is discharge coefficient and $x$ is the discharge exponent.

\section{Radius of throw}

The large cannon sprinkler was operated at different operating pressures and the radius of throw was measured using a measuring tape.

\section{Average precipitation rate}

There are great differences between natural precipitation and large cannon sprinkler precipitation. One is the application rate change with the radius of throw, and it can cause the water distribution nonuniform. The other is the spraying is intermittent for the field due to the large cannon sprinkler is rotary when it works. So, average application rate was selected as one hydraulic performance index to evaluate large cannon sprinkler.

The rate that water falls to the ground is called average precipitation rate. It is usually reported in units of millimeter per hour. Precipitation rate is important to designer for at least two reasons: (1) designer want to avoid applying water at a faster rate than the soil can absorb it, and (2) designer need precipitation rate to compute the time required to apply a desired depth of water. Precipitation rate is simply the flow into an area divided by the area:

$$
I=\frac{Q}{S}
$$

Where: I is average precipitation rate in $\mathrm{mm} \cdot \mathrm{h}^{-1} ; Q$ is sprinkler discharge in $\mathrm{m}^{3} \cdot \mathrm{h}^{-1}$; and $S$ is surface area irrigated by sprinkler in $\mathrm{m}^{2}$.

\section{Christiansen's uniformity coefficient}

Sprinkler irrigation uniformity coefficient mainly reflect the distribution of the water volume in the irrigation area of homogeneous degree, it has a decisive influence on the growth of crops, is one of the important indexes to measure quality of sprinkler irrigation. Christiansen's uniformity coefficient (Christiansen 1942) was defined to evaluate sprinkler irrigation systems and has the strongest historical precedent in the sprinkler irrigation industry. It is defined as:

$$
\mathrm{CU}=100\left[1.0-\frac{\sum\left|x_{i}-x_{m}\right|}{\sum x_{i}}\right]
$$

Where: CU is Christiansen's uniformity coefficient, \%. $x_{i}$ is measured depth (volume or mass) of water in equally spaced catch cans on a grid; $x_{m}$ is mean depth (volume or mass) of water of the catch in all cans.

Matrix laboratory (MATLAB) was used as the computational program to calculate the combined $\mathrm{CU}$ values according to the radial application rate of water distribution. In this work, two common different layout forms were adopt to analysis the effects of different layout form and overlapping distance on $\mathrm{CU}$ values. Figure 3 presents the two different layout forms, one is square layout and the other is equilateral triangle layout. Spacing coefficient was defined as a parameter to describe the overlapping distance of two sprinklers for two different layout forms, and spacing coefficient was equal to the times of radius of throw. As can be seen from Fig. 3a, the relationship between overlapping distance and radius of throw can be presented as follow:

$$
l=S_{d} \cdot R(4)
$$

Where: I is overlapping distance of two sprinklers in $\mathrm{m}, S_{d}$ is spacing coefficient, $R$ is radius of throw in $\mathrm{m}$. The maximum $S_{d}$ can be achieved for square layout 
from Fig. $3 a$ and the value was 1.41. In the same way, the maximum $S_{d}$ can be achieved for equilateral triangle layout from Fig. $3 \mathrm{~b}$ and the value was 1.73. When the spacing coefficient exceeded 1.41 or 1.73 with square or equilateral triangle layout respectively, some area cannot be irrigated with the sprinkler. Therefore, five different spacing coefficients were selected for square layout, 1.0, 1.1, 1.2, 1.3 and 1.4. And eight different spacing coefficients were selected for equilateral triangle layout,.

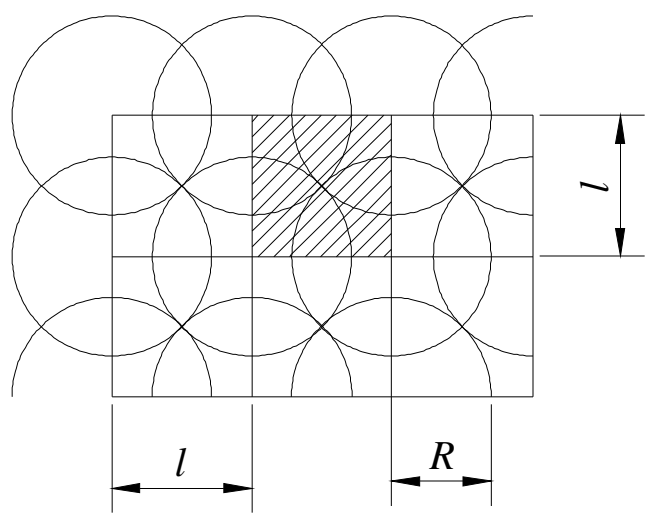

(a)

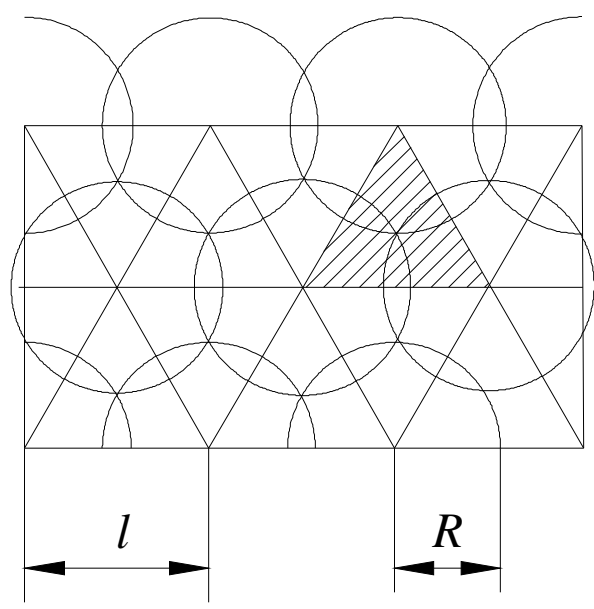

(b)

Figure 3: Two different layout forms of large cannon sprinkler. (a) Square layout, (b) Equilateral triangle layout

\section{RESULTS AND DISCUSSION}

\section{Sprinkler flow rate}

Figure 4 shows the results of flow rate under different operating pressures and nozzle diameters. The flow rate of the large cannon sprinkler increased with operating pressure and nozzle diameter.

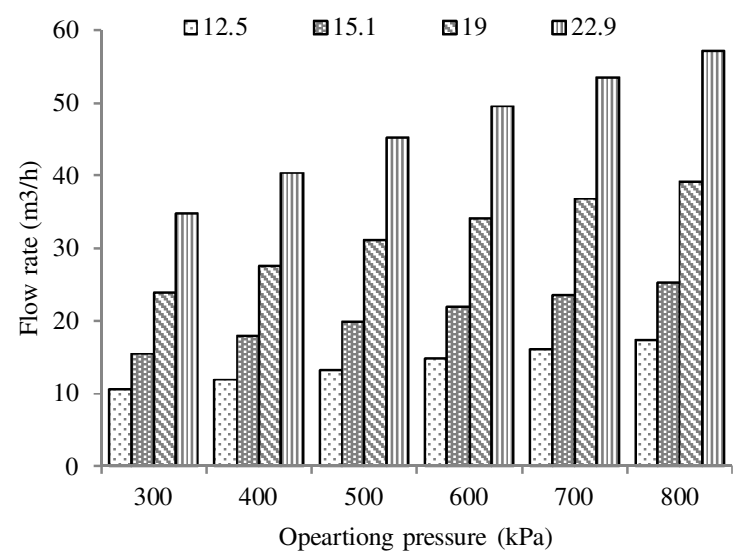

Figure 4: Flow rate of large cannon sprinkler under different operating pressure and nozzle diameter

With regard to the discharge equation (Eq. (1)), several studies applied to agricultural sprinklers interpreted that discharge exponent is essentially independent of operating pressure for a given nozzle diameter and that discharge exponent is constant and equal to 0.5 (Li, 1996; Li and Kawano, 1998; Tarjuelo et al., 1999a). We also assumed discharge exponent to be equal to 0.5 .

Table 1 shows a summary of the calculated results of the discharge coefficient under different operating pressures and nozzle diameters. The discharge coefficient ranged from 0.96 to 0.99 , and it remained basically unchanged for the entire range of operating pressures with each nozzle diameter. Small differences were due to experimental error themselves. This indicated that the discharge coefficient was independent of the operating pressure. The discharge coefficients that were showed in table 1 and Eq. (3) allowed us to calculate flow rate for every operating pressure and nozzle diameter. 
Table 1: Discharge coefficient under different operating pressures and nozzle diameters

\begin{tabular}{ccccc}
\hline Operating & \multicolumn{4}{c}{ Nozzle diameter $(\mathrm{mm})$} \\
\cline { 2 - 5 } $\begin{array}{c}\text { pressure } \\
(\mathrm{kPa})\end{array}$ & 12.5 & 15.1 & 19 & 22.9 \\
\hline 300 & 0.99 & 0.99 & 0.97 & 0.97 \\
400 & 0.96 & 0.99 & 0.96 & 0.97 \\
500 & 0.95 & 0.99 & 0.98 & 0.97 \\
600 & 0.97 & 0.99 & 0.98 & 0.97 \\
700 & 0.98 & 0.99 & 0.98 & 0.97 \\
800 & 0.99 & 0.99 & 0.97 & 0.97 \\
\hline
\end{tabular}

Radius of throw

The relationship between radius of throw and operating pressures under different nozzle diameters is shown in Figure 5. The results showed that there is a linear relationship between the radius of throw and operating pressures under the same nozzle diameter and the radius of throw increased with the increase of operating pressure. Under the same operating pressure, the radius of throw increased with the increase of nozzle diameter. When the nozzle diameter was $12.5 \mathrm{~mm}$, the radius of throw was $27 \mathrm{~m}$ and $38 \mathrm{~m}$ at 300 and $800 \mathrm{kPa}$, respectively, and the growth range was $11 \mathrm{~mm}$. When the nozzle diameter was $22.9 \mathrm{~mm}$, the radius of throw was $38 \mathrm{~m}$ and $52 \mathrm{~m}$ at $300 \mathrm{kPa}$ and $800 \mathrm{kPa}$, respectively, and the growth range was $14 \mathrm{~mm}$. This indicated that the growth range of radius of throw with larger nozzle diameter was bigger than smaller nozzle diameter when the same operating pressure was increased. A regress equation about the radius of throw and operating pressure and nozzle diameter was built by using the regression analysis, and the model was proposed as follow:

$$
R=0.0164 \cdot p \cdot \mathrm{e}^{0.0242 d}+15.534 \cdot \ln (d)-18.861
$$

Where: $R$ is radius of throw in $\mathrm{m}, p$ is operating pressure in $\mathrm{kPa}, d$ is nozzle diameter in $\mathrm{mm}$, and the coefficient of determination is 0.9765 .

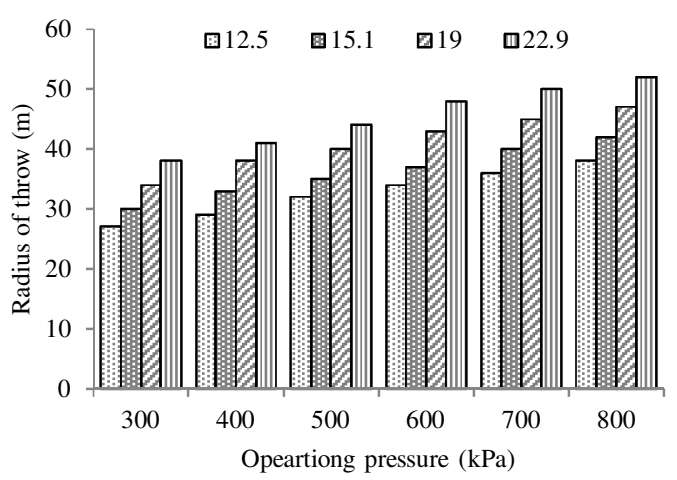

Figure 5: Radius of throw of large cannon sprinkler under different operating pressures and nozzle diameters

\section{Sprinkler water distribution pattern}

Due to the shape of water distribution under different nozzle diameters versus the distance from sprinkler had the similar rule, therefore, the water distribution patterns under the nozzle diameter was $12.5 \mathrm{~mm}$ were selected to analyze the effect of different operating pressure on water distribution pattern. A graphic representation of single-radius sprinkler water distribution patterns with the nozzle diameter was $12.5 \mathrm{~mm}$ obtained in tests is shown in Figure 6. Comparing the six water distribution patterns, curves with triangular shape can be observed at the end of radius of throw. Also, it can be observed that the application rate was lower near the sprinkler (1-3 m) because of the secondary nozzle was not used, and then a peak value of application rate was occurred under the radius of throw from 4 to $6 \mathrm{~m}$ for each water distribution pattern. When the operating pressures (300, 400 and $500 \mathrm{kPa}$ ) were relatively lower, the application rates at the end of radius of throw declined dramatically. When the operation pressures $(600,700$ and $800 \mathrm{kPa}$ ) were relatively higher, the application rates at the end of radius of throw declined slowly. When the operating pressure exceed $500 \mathrm{kPa}$, the application rate at the middle radius of throw had a good consistency and water distribution uniformity. 


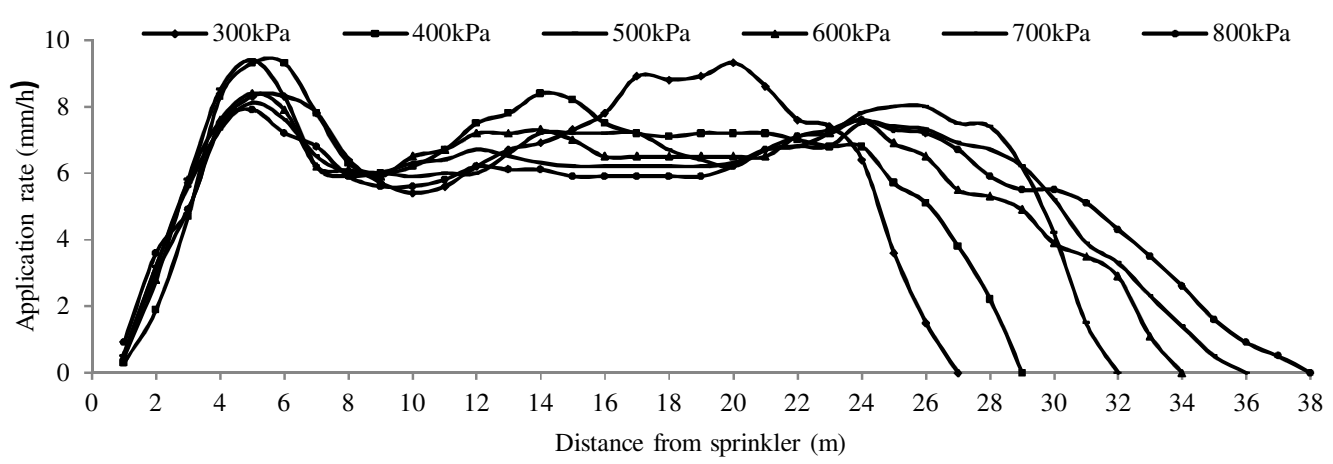

Figure 6: Water distribution patterns of the large cannon sprinkler with the nozzle diameter is $12.5 \mathrm{~mm}$ under different operation pressures $(300,400,500,600,700$ and $800 \mathrm{kPa})$

\section{Average application rate}

Figure 7 shows the average application rate of the large cannon sprinkler under different operating pressures and nozzle diameters. The average application rate decreased with the increase in operating pressure. This was due to the flow rate and surface area irrigated by large cannon sprinkler were increased with the increase of operation pressure, but the growth range of surface area was bigger than flow rate, so that the average application rate was decreased. The average application rate increased with increase in nozzle diameter. This was due to the growth range of flow rate was bigger than surface area. When the operating pressure was $300 \mathrm{kPa}$, the average application rate were 4.62, 5.47, 6.57 and $7.66 \mathrm{~mm} / \mathrm{h}$ with the nozzle diameter were $12.5,15.1$, 19 and $22.9 \mathrm{~mm}$, respectively. When the operating pressure was $800 \mathrm{kPa}$, the average application rate were $3.83,4.56,5.64$ and $6.72 \mathrm{~mm} / \mathrm{h}$. Therefore, the decreased in magnitudes were $0.79,0.91,0.93$ and $0.94 \mathrm{~mm} / \mathrm{h}$ respectively, which indicates that the increase or decrease in magnitude of average application rate under small nozzle diameter was larger than the large nozzle diameter within the same range of variation of operating pressure.

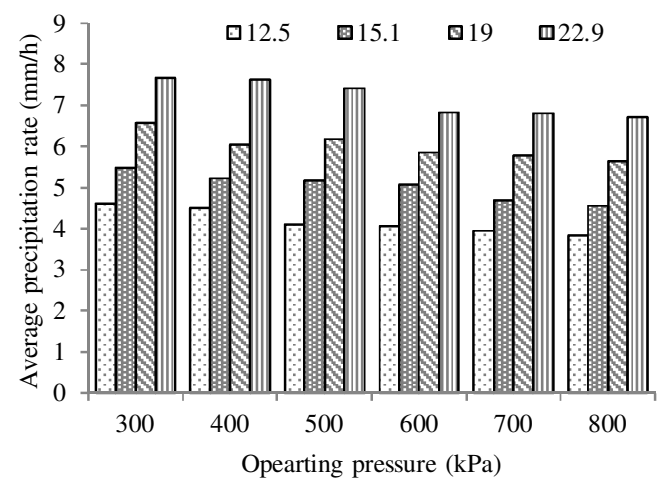

Figure 7: Average application rate of large cannon sprinkler under different operating pressures and nozzle diameters

Uniformity coefficient analysis for square layout

The $\mathrm{CU}$ values under different operating pressures $(300,400,500,600,700$ and $800 \mathrm{kPa})$, nozzle diameters (12.5, 15.1, 19 and $22.9 \mathrm{~mm}$ ) and spacing coefficients (1.0, 1.1, 1.2, 1.3 and 1.4) for square layout in no wind conditions were shown in figure 8.

Figure 8(a) presents the $\mathrm{CU}$ values with the nozzle diameter is $12.5 \mathrm{~mm}$. As it can be seen in Fig. $9 \mathrm{a}$, at $300 \mathrm{kPa}$, the maximum CU was $68.5 \%$ with spacing coefficient was 1.4 , the minimum $\mathrm{CU}$ was $59.2 \%$ with spacing coefficient was 1.3. At $400 \mathrm{kPa}$, the maximum $\mathrm{CU}$ was $69.1 \%$ with spacing coefficient was 1.4 , and the minimum CU was $60.5 \%$ with 
spacing coefficient was 1.1. At $500 \mathrm{kPa}, \mathrm{CU}$ changed slightly with the increase of spacing coefficient, and $\mathrm{CU}$ values were around $73 \%$. At $600 \mathrm{kPa}, \mathrm{CU}$ values decreased with the increase of spacing coefficient, and the maximum $\mathrm{CU}$ was $76.2 \%$ with spacing coefficient was 1.0. The maximum CU was $80.1 \%$ with spacing coefficient of 1.0 at $700 \mathrm{kPa}$. When the operating pressure was $500 \mathrm{kPa}$, the $\mathrm{CU}$ value changed slightly to $82 \%$ with the increase of spacing coefficient.

Figure $8(\mathrm{~b})$ presents the $\mathrm{CU}$ values with nozzle diameter of $15.1 \mathrm{~mm}$. For $300 \mathrm{kPa}$, the maximum CU was $67.5 \%$ with spacing coefficient was 1.4 , the minimum $\mathrm{CU}$ was $57.5 \%$ with spacing coefficient of 1.2. At $400 \mathrm{kPa}$, the maximum $\mathrm{CU}$ was $69.1 \%$ with spacing coefficient was 1.4 , the minimum $\mathrm{CU}$ was $60.2 \%$ with spacing coefficient was 1.3 . However, at $500 \mathrm{kPa}$ a maximum $\mathrm{CU}$ of $73.6 \%$ with spacing coefficient of 1.0 , and the minimum $\mathrm{CU}$ was $69.1 \%$ with spacing coefficient of 1.2. Additionally, at $600 \mathrm{kPa}$, the maximum $\mathrm{CU}$ was $72.5 \%$ with spacing coefficient of 1.0 , the minimum CU was $64.5 \%$ with spacing coefficient was 1.4. The $\mathrm{CU}$ values decreased initially and finally remained stable at 700 $\mathrm{kPa}$, with the increase of spacing coefficient, and the maximum $\mathrm{CU}$ was $78.8 \%$ with spacing coefficient of 1.0. At $800 \mathrm{kPa}, \mathrm{CU}$ values decreased with the increase of spacing coefficient, and the maximum $\mathrm{CU}$ was $83.5 \%$ with spacing coefficient of 1.0 .

Figure 8(c) shows the $\mathrm{CU}$ values for the nozzle diameter $19 \mathrm{~mm}$. At $300 \mathrm{kPa}$, the maximum CU was $61.3 \%$ with spacing coefficient was 1.0 , the minimum $\mathrm{CU}$ was $55.6 \%$ with spacing coefficient was 1.2. At $400 \mathrm{kPa}$, the maximum $\mathrm{CU}$ was $65.1 \%$ with spacing coefficient was 1.0, the minimum $\mathrm{CU}$ was $57.2 \%$ with spacing coefficient of 1.4 . The $500 \mathrm{kPa}$ recorded a maximum $\mathrm{CU}$ of $67.8 \%$ with spacing coefficient of 1.0, and the minimum CU recorded was $62.1 \%$ with spacing coefficient of 1.2 . For $600 \mathrm{kPa}$, the maximum $\mathrm{CU}$ was $71.6 \%$ with spacing coefficient of 1.2 , and the minimum $\mathrm{CU}$ was $64.2 \%$ with spacing coefficient of 1.4 . Further, at $700 \mathrm{kPa}$, the maximum CU was $77.2 \%$ with spacing coefficient was 1.4 , the minimum CU was $71.6 \%$ with spacing coefficient of 1.1. Similarly, the $800 \mathrm{kPa}$ had a maximum $\mathrm{CU}$ was $81.7 \%$ with spacing coefficient of 1.2 , however the CU values decreased rapidly with the increase of spacing coefficient.

Figure 8(d) presents the $\mathrm{CU}$ values with the nozzle diameter is $22.5 \mathrm{~mm}$. The $300 \mathrm{kPa}$ had a maximum $\mathrm{CU}$ of $62.5 \%$ with spacing coefficient of 1.0 , and the minimum $\mathrm{CU}$ was $55.6 \%$ with spacing coefficient of 1.1. In addition, the $400 \mathrm{kPa}$ recorded a maximum $\mathrm{CU}$ of $62.6 \%$ with spacing coefficient of 1.4 , and the minimum $\mathrm{CU}$ was $56.4 \%$ with spacing coefficient of 1.1. However, the $500 \mathrm{kPa}, \mathrm{CU}$ changed slightly with the increase of spacing coefficient, and $\mathrm{CU}$ values was about $63 \%$. At $600 \mathrm{kPa}$, the maximum $\mathrm{CU}$ was $68.6 \%$ with spacing coefficient was 1.4 , the minimum CU was $59.4 \%$ with spacing coefficient was 1.2. For the $700 \mathrm{kPa}$, the maximum CU was $72.6 \%$ with spacing coefficient of 1.2 , and the minimum $\mathrm{CU}$ was $65.5 \%$ with spacing coefficient of 1.4 . At $800 \mathrm{kPa}$, $\mathrm{CU}$ values increased initially and finally decreased with the increase of spacing coefficient, and the maximum CU was $78.4 \%$ with spacing coefficient of 1.1.

From the above analysis, it can be concluded that $\mathrm{CU}$ values increased with the increase in operation pressure and decreased with the nozzle diameter. Also, the optimum spacing coefficients under different operating pressure were not same. 


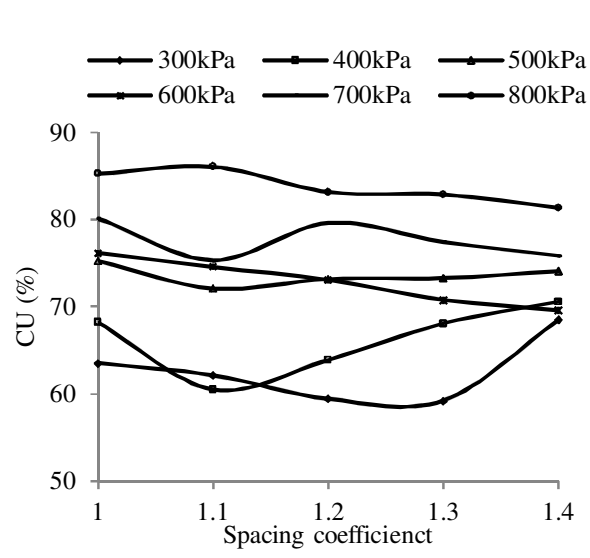

(a)

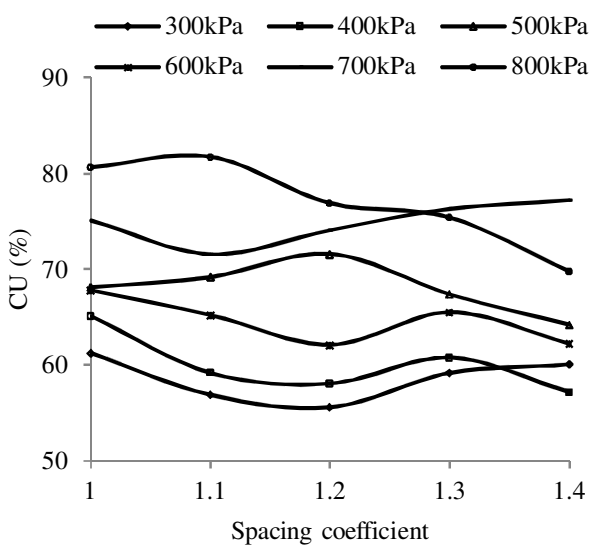

(c)

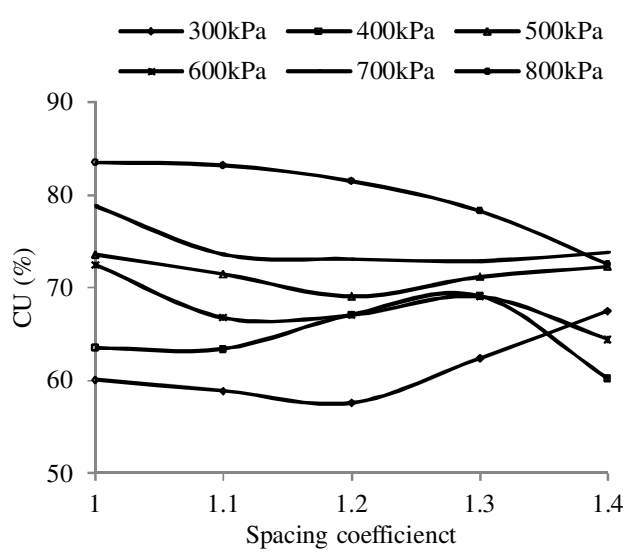

(b)

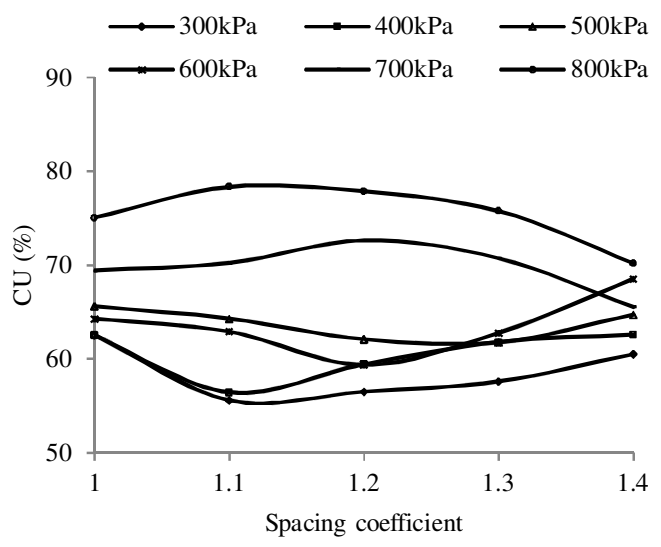

(d)

Figure 8: The $\mathrm{CU}$ values under different nozzle diameters $(12.5,15.1,19$ and $22.5 \mathrm{~mm})$, operating pressure $(300,400,500,600,700$ and $800 \mathrm{kPa})$ and spacing coefficient $(1.0,1.1,1.2,1.3$ and 1.4) for square layout. (a) Nozzle diameter is $12.5 \mathrm{~mm}$, (b) Nozzle diameter is $15.1 \mathrm{~mm}$, (c) Nozzle diameter is $19 \mathrm{~mm}$, (d) Nozzle diameter is $22.5 \mathrm{~mm}$.

Uniformity coefficient analysis for equilateral triangle layout

The $\mathrm{CU}$ values under different operating pressures $(300,400,500,600,700$ and $800 \mathrm{kPa})$, nozzle diameters (12.5, 15.1, 19 and $22.9 \mathrm{~mm}$ ) and spacing coefficients $(1.0,1.1,1.2,1.3,1.4,1.5,1.6$ and 1.7) for equilateral triangle layout in no wind conditions were shown in figure 9 .

Figure 9(a) presents the $\mathrm{CU}$ values with the nozzle diameter is $12.5 \mathrm{~mm}$. At $300 \mathrm{kPa}, \mathrm{CU}$ values increased firstly and then decreased with the increase of spacing coefficient, and the maximum $\mathrm{CU}$ was $65.7 \%$ with spacing coefficient was 1.3. At $400 \mathrm{kPa}$, $\mathrm{CU}$ values changed small, and the maximum $\mathrm{CU}$ was $72.7 \%$ with spacing coefficient was 1.7 . At $500 \mathrm{kPa}$, $\mathrm{CU}$ values decreased firstly and then increased with the increase of spacing coefficient, and the maximum
CU was $78 \%$ with spacing coefficient was 1.6 . At 600 $\mathrm{kPa}, \mathrm{CU}$ values decreased slowly with the increase of spacing coefficient, and the maximum CU was $79.6 \%$ with spacing coefficient was 1.0 . At $700 \mathrm{kPa}$, the maximum $\mathrm{CU}$ was $86.1 \%$ with spacing coefficient was 1.6. At $800 \mathrm{kPa}, \mathrm{CU}$ values changed small and were around $84 \%$.

Figure 9(b) presents the $\mathrm{CU}$ values with the nozzle diameter is $15.1 \mathrm{~mm}$. At $300 \mathrm{kPa}, \mathrm{CU}$ values presented normal distribution along spacing coefficient, and the maximum CU was 66.9 with spacing coefficient was 1.4 . At $400 \mathrm{kPa}$, CU values increased firstly and then decreased, the maximum $\mathrm{CU}$ was $73.1 \%$ with spacing coefficient was 1.5 . At $500 \mathrm{kPa}, \mathrm{CU}$ values decreased with the increase of spacing coefficient, and the maximum $\mathrm{CU}$ was 74.1 with spacing coefficient was 1.0 . At $600 \mathrm{kPa}$, the maximum $\mathrm{CU}$ was 76.4 with spacing coefficient was 
1.1. At $700 \mathrm{kPa}$, the maximum CU was $83.5 \%$ with spacing coefficient was 1.5.At $700 \mathrm{kPa}, \mathrm{CU}$ values kept stable firstly and then decreased, the maximum CU was $83.5 \%$ with spacing coefficient was 1.3 .

Figure 9(c) presents the $\mathrm{CU}$ values with the nozzle diameter is $19 \mathrm{~mm}$. At $300 \mathrm{kPa}, \mathrm{CU}$ values decreased firstly and then increased with the increase of spacing coefficient, and the maximum $\mathrm{CU}$ was $68.2 \%$ with spacing coefficient was 1.7 . At $400 \mathrm{kPa}$, $\mathrm{CU}$ values changed small and the maximum $\mathrm{CU}$ was 68.2 with spacing coefficient was 1.0. At $500 \mathrm{kPa}, \mathrm{CU}$ values decreased with the increase of spacing coefficient, and the maximum CU was $74.1 \%$ with spacing coefficient was 1.0 . At $600 \mathrm{kPa}, \mathrm{CU}$ values decreased firstly and then increased, the maximum CU was $75.6 \%$ with spacing coefficient was 1.0 . At
$700 \mathrm{kPa}$, the maximum $\mathrm{CU}$ was $81.7 \%$ with spacing coefficient was 1.6. At $800 \mathrm{kPa}, \mathrm{CU}$ values increased firstly and then decreased, the maximum $\mathrm{CU}$ was $82.7 \%$ with spacing coefficient was 1.4 .

Figure 9(d) presents the $\mathrm{CU}$ values with the nozzle diameter is $22.5 \mathrm{~mm}$. At $300 \mathrm{kPa}, \mathrm{CU}$ values decreased firstly and then increased, the maximum CU was $63.7 \%$ with spacing coefficient was 1.4 . At $400 \mathrm{kPa}$, the maximum $\mathrm{CU}$ was $67.3 \%$ with spacing coefficient was 1.2. At $500 \mathrm{kPa}, \mathrm{CU}$ values decreased firstly and then increased, the maximum CU was 70.6 with spacing coefficient was 1.0 . At $600 \mathrm{kPa}$, the maximum $\mathrm{CU}$ was 70.6 with spacing coefficient was 1.0. At $700 \mathrm{kPa}$, the maximum $\mathrm{CU}$ was 78.2 with spacing coefficient was 1.7. At $800 \mathrm{kPa}$, the maximum CU was 79.5 with spacing coefficient was 1.3 .

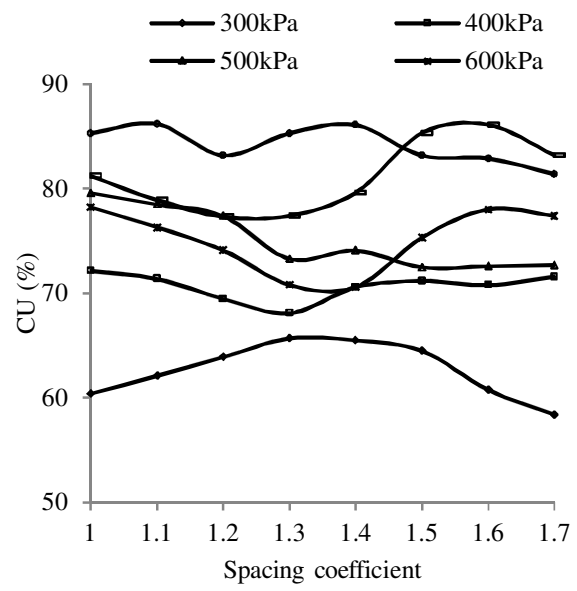

(a)

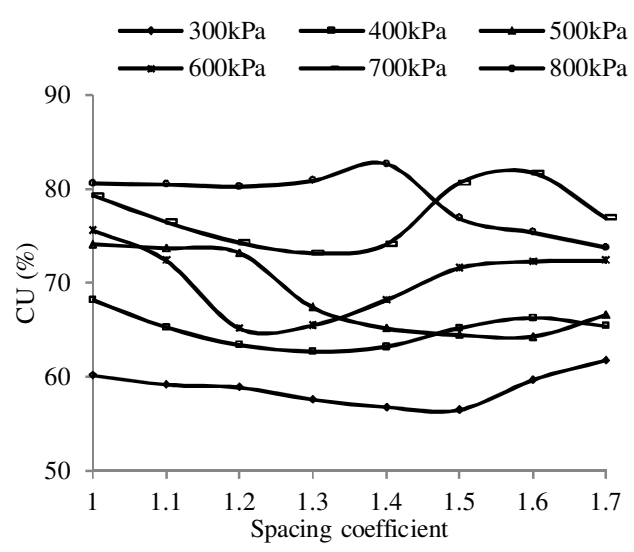

(c)

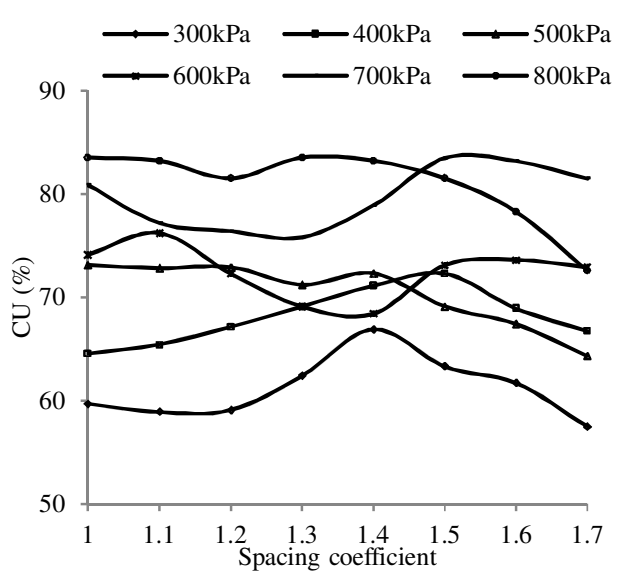

(b)

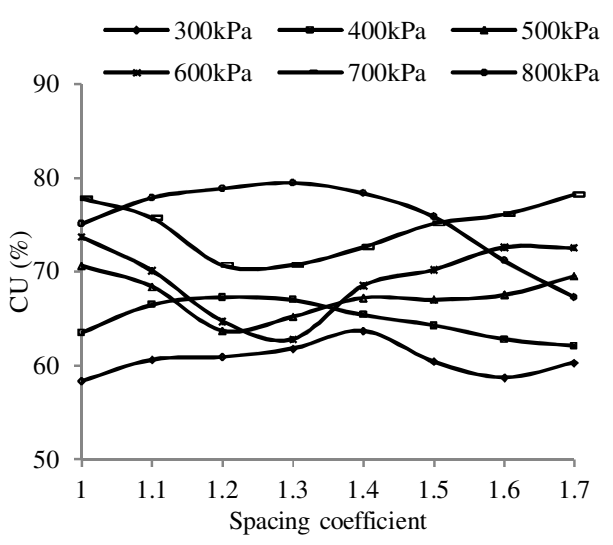

(d)

Figure 9: The CU values under different nozzle diameters $(12.5,15.1,19$ and $22.5 \mathrm{~mm})$, operating pressure $(300,400,500,600,700$ and $800 \mathrm{kPa})$ and spacing coefficient $(1.0,1.1,1.2,1.3$ and 1.4) for equilateral triangle layout. (a) Nozzle diameter is $12.5 \mathrm{~mm}$, (b) Nozzle diameter is $15.1 \mathrm{~mm}$, (c) Nozzle diameter is $19 \mathrm{~mm}$, (d) Nozzle diameter is $22.5 \mathrm{~mm}$. 


\section{Recommendation}

Table 2 presents the optimal CU values and spacing coefficients of large cannon sprinkler with different conditions of layout, operating pressure and nozzle diameter. This table can be readily applied to the design of irrigation system equipped with this type of large cannon sprinkler. As seen from the table, the maximum $\mathrm{CU}$ values increased with the increase of operating pressure under different nozzle diameter or different layout. Equilateral triangle layout achieved higher uniformities compared with square layout.

Table 2: The Optimal CU values and spacing coefficients of large cannon sprinkler with different conditions of layout, operating pressure and nozzle diameter

\begin{tabular}{|c|c|c|c|c|c|c|c|c|c|c|c|c|c|c|c|c|}
\hline \multirow{3}{*}{$\begin{array}{l}\text { Operating } \\
\text { pressure }\end{array}$} & \multicolumn{8}{|c|}{ Square } & \multicolumn{8}{|c|}{ Equilateral triangle } \\
\hline & \multicolumn{2}{|c|}{12.5} & \multicolumn{2}{|c|}{15.1} & \multicolumn{2}{|c|}{19} & \multicolumn{2}{|c|}{22.9} & \multicolumn{2}{|c|}{12.5} & \multicolumn{2}{|c|}{15.1} & \multicolumn{2}{|c|}{19} & \multicolumn{2}{|c|}{22.9} \\
\hline & $S_{d}$ & $\mathrm{CU}$ & $S_{d}$ & $\mathrm{CU}$ & $S_{d}$ & $\mathrm{CU}$ & $S_{d}$ & $\mathrm{CU}$ & $S_{d}$ & $\mathrm{CU}$ & $S_{d}$ & $\mathrm{CU}$ & $S_{d}$ & $\mathrm{CU}$ & $S_{d}$ & $\mathrm{CU}$ \\
\hline 300 & 1.4 & 68.5 & 1.4 & 67.5 & 1.0 & 61.3 & 1.0 & 62.5 & 1.3 & 65.7 & 1.3 & 62.4 & 1.7 & 61.8 & 1.4 & 63.7 \\
\hline 400 & 1.4 & 70.6 & 1.3 & 69.1 & 1.0 & 65.1 & 1.4 & 62.6 & 1.0 & 72.2 & 1.5 & 72.3 & 1.0 & 68.2 & 1.2 & 67.3 \\
\hline 500 & 1.0 & 75.3 & 1.0 & 73.6 & 1.3 & 71.6 & 1.0 & 65.6 & 1.0 & 79.6 & 1.0 & 73.1 & 1.0 & 74.1 & 1.0 & 70.6 \\
\hline 600 & 1.0 & 76.2 & 1.0 & 72.5 & 1.0 & 67.8 & 1.4 & 68.5 & 1.0 & 78.2 & 1.2 & 76.2 & 1.0 & 75.6 & 1.0 & 73.7 \\
\hline 700 & 1.0 & 80.1 & 1.0 & 78.8 & 1.4 & 77.2 & 1.3 & 72.6 & 1.6 & 86.1 & 1.5 & 83.5 & 1.6 & 81.7 & 1.7 & 78.2 \\
\hline 800 & 1.1 & 86.1 & 1.0 & 83.5 & 1.2 & 81.7 & 1.2 & 78.4 & 1.2 & 86.2 & 1.3 & 83.7 & 1.4 & 82.7 & 1.3 & 79.5 \\
\hline
\end{tabular}

\section{CONCLUSIONS}

Appropriate selection of sprinkler plays an important role in the performance of modern irrigation system. Relevant factors of large cannon sprinkler affecting the irrigation performance are the nozzle diameter, operating pressure, layout form, and overlapping distance. All these factors were studied in the present work to develop guidelines for adequate design of irrigation system with the large cannon sprinkler SR100-24, and the following conclusions were drawn:

1. For sprinkler discharge, the discharge coefficient ranged from 0.96 to 0.99 . A mathematical model of radius of throw was also regressed and the coefficient of determination was 0.9765 .

2. The application rate was lower near the sprinkler, and then a peak value was occurred under the radius of throw from 4 to $6 \mathrm{~m}$ for each water distribution pattern. The average application rate was decreased with the increase of operating pressure. The average application rate increased with the increase of nozzle diameter. The increased or decreased magnitude of average application rate under small nozzle diameter was larger than large nozzle diameter within the same range of variation of operating pressure.

3. The maximum $\mathrm{CU}$ values increased with increase in operating pressure under different nozzle diameter or different layout forms. Triangular layout achieved higher uniformities compared with square layout. The optimal CU values and spacing coefficients of the large cannon sprinkler with different conditions of layout, operating pressure and nozzle diameter were proposed.

\section{REFERENCES}

ASAE Standards, 32nd Ed. S330.1 (1985) Procedure for sprinkler distribution testing for research purposes. St. Joseph, Mich.,ASAE

ASAE Standards, 32nd Ed. S398.1 (1985) Procedure for sprinkler testing and performance reporting. St. Joseph, Mich., ASABE

Burt, C.M., Clemmens, A.J., Strelkoff, T.S., Solomon, 
K.H., Bliesner, R.D., Hardy, L.A., Howell, T.A., Eisenhauer, D.E., 1997. Irrigation performance measures: efficiency and uniformity. J. Irrig. Drain. Eng. 123 (6), 423-442.

Burillo GS, Delirhasannia R, Playán E (2013) Initial drop velocity in a fixed spray plate sprinkler. $\mathrm{J}$ Irrig Drain Eng ASCE139(7):521-531

Branscheid VO, Hart WE. 1986. Predicting field distribution of sprinkler systems. Transactions of the ASAE 11: 801-803.

Chen D, Wallender WW (1985) Droplet size distribution and water application with lowpressure sprinklers. Trans ASAE 28(2):511-516

Carrion, P., Tarjuelo, J.M., Montero, J., 2001. SIRIAS: a simulation model for sprinkler irrigation: I. Description of model. Irrig. Sci. 20, 73-84.

Christiansen, J.E., 1942. Irrigation by Sprinkling. California Agricultural Experimental Station Bulletin 670. Univ. California, USA.

Carrión, P.; Tarjuelo, J. M.; Monteiro, J. SIRIAS: a simulation model for sprinkler irrigation. I Description of model. Irrigation Science, v.20, p.73-84, 2001.

Culver R, Sinker RF (1966) Rapid assessment of sprinkler performance. J Irrig Drain Div ASCE 92(1):1-17

Canessa, P., Hermanson, R.E., 1994. Irrigation Management Practices to Protect Groundwater and Surface Water Quality State of Washington. Em4885.Washington State of Ecology, Olympia, USA.

Dukes MD. 2006. Effect of wind speed and pressure on linear move irrigation system uniformity. Applied Engineering in Agriculture 22(4):541548.

Edling RJ (1985) Kinetic energy, evaporation and wind drift of droplets from low pressure irrigation nozzles. Trans ASAE 28(5):1543-1550

Faci JM, Salvador R, Playan E, Sourell H (2001) Comparison offixed and rotating spray plate sprinklers. J Irrig Drain Eng ASCE127(4):224233

Faci JM, Salvador R, Playan E, Sourell H (2001) Comparison offixed and rotating spray plate sprinklers. J Irrig Drain Eng ASCE127(4):224233

Fukui Y, Nakanishi K, Okamura S (1980) Computer evaluation of sprinkler irrigation uniformity. Irrig Sci 2:23-32

ISO 7749-2.(1990), MOD GB/T 19795.2. (2005) Agricultural irrigation equipment-rotating sprinklers-part 2: uniformity of distribution and test methods. International Standards Organization

James, L.G., Blair, S.K., 1984. Effect of Wind on Center Pivot Application Uniformity .ASAE 842581, St. Joseph, MI, USA.

Keller, J., Bliesner, R.D., 1990. Sprinkle and Trickle Irrigation AVI Book. Van Nostrand Reinhold, New York, USA.

Li, J.S., 1996. Sprinkler performance as function of nozzle geometrical parameters. Journal of Irrigation and Drainage Engineering - ASCE122 (4), 244-247.

Li, J.S., Kawano, H., 1998. Sprinkler performance as affected by nozzle inner contraction angle. Irrigation Science 18, 63-66.

Louie MJ, Selker JS (2000) Sprinkler head maintenance effects on water application uniformity. J Irrig Drain Eng ASCE 126(3):142148

Liu JP, Yuan SQ, Li H, Zhu XY (2013a) Numerical simulation and experimental study on a new type variable-rate fluidic sprinkler. J Agric Sci Techol 15(3):569-581

Mateos L (2006) A Simulation study of comparison of the evaluation procedures for three irrigation methods. Irrig Sci 25(1):75-83

Salmerón, M., Urrego, Y. F., Isla, R., Cavero J., Effect of non-uniform sprinkler irrigation and plant density on simulated maize yield, Journal of Agricultural Water Management113 (2012) 1-9.

Mateos, L., 1998. Assessing whole field uniformity of stationary sprinkler irrigation systems. Irrigation Science 18 (2), 73-81.

Siosemarde M., Byzedi M., Studding of Sprinkler Irrigation Uniformity, World academy of Science Engineering and Technology (2012) 574-575.

Osman M, Hassan S B, Yusof K B W. Effect of Combination Factors of Operating Pressure, Nozzle Diameter and Riser Height on Sprinkler Irrigation Uniformity[J]. Applied Mechanics \& Materials, 2014, 695:380-383.

Pascal, M, Kadem. N, Tchiftchibachian, A. (2006) 
Investigation of the influence of sprinkler fins and dissolved air on jet flow. Journal of Irrigation and Drainage Engineering, 132(1): 41-46.

Playán, E.; Zapata; N. Faci, J. M.; Tolosa, D.; Lacuerva, J. L.; Pelegri, J; Salvador, R.; Sanches, I.; Lafita, A. Assessing sprinkler irrigation uniformity using a ballistic simulation model. Agricultural Water Management, v.84, p.89-100, 2006.

Solomon, K.H., 1983. Irrigation Uniformity and Yield Theory, Doctoral Thesis. Univ. Utah State, USA.

Sourell H, Faci JM, Playan E (2003) Performance of rotating spray plate sprinklers in indoor experiments. J Irrig Drain Eng ASCE129(5):376380

Seginer, I., Nir, D., Von Bernuth, R.D.,1991b. Simulation of wind-distorted sprinkler patterns. J. Irrig. Drain. Eng. 117 (2), 285-306.

Silva, L. L. (2006). The effect of spray head sprinklers with different deflector plates on irrigation uniformity, runoff and sediment yield in a Mediterranean soil. Agricultural Water
Management, 85(3): 243-252.

Seginer, I.; Kantz, D.; Nir, D.; Bernuth, R. D. von. Indoor measurement of single-radius sprinkler patterns. Transactions of the American Society of Agricultural Engineers, v.35, p.523-533, 1992.

Tarjuelo, J.M., Montero, J., Carrión, P.A., Honrubia, F.T., Calvo, M.A., 1999a. Irrigation uniformity with medium size sprinklers. Part II: influence of wind and other factors on water distribution. T ASAE 42 (3), 677-689.

Tarjuelo, J.M., Montero, J., Valiente, M., Honrubia, F.T., Ortiz, J.J., 1999c. Irrigation uniformity with medium size sprinklers Part I. Characterization of water distribution in no-wind conditions. ASAE 42 (3), 665-675.

Zhang, L.; Merkley, G. P.; Kasem, P. Assessing wholefield sprinkler irrigation application uniformity. Irrigation Science, v.31, p.87-105, 2013

Zhu XY, Yuan SQ, Liu JP (2012) Effect of sprinkler head geometrical parameters on hydraulic performance of fluidic sprinkler. J Irrig Drain Eng ASCE 138(11):1019-1026.

Cite this Article: Issaka Z, Issah MH, Yamba P (2018). Investigation of Water Distribution Characteristics for Large Cannon Irrigation Sprinkler under different Spacing and Layouts. Greener Journal of Science, Engineering and Technological Research, 8(1): 001-013, http://doi.org/10.15580/GJSETR.2018.1.040618056. 